Check for updates

Cite this: Chem. Commun., 2020, 56,12142

Received 21st June 2020,

Accepted 17th September 2020

DOI: $10.1039 / \mathrm{d} 0 \mathrm{cc} 04310 \mathrm{a}$

rsc.li/chemcomm

\section{Hydrogenation and electrocatalytic reduction of carbon dioxide to formate with a single Co catalyst $\uparrow$}

\author{
Fang Wang, (D) Austin T. Cannon, (D) Moumita Bhattacharya, (D) Robert Baumgarten, \\ Ryan T. VanderLinden (D) and Caroline T. Saouma (D) *
}

\begin{abstract}
A cobalt(1) complex is shown to be capable of both electrocatalytic reduction and hydrogenation of $\mathrm{CO}_{2}$ to formate. Several proposed intermediates are characterized and thus form the basis for a proposed mechanism that allows for the dual reactivity: reduction of $\mathrm{CO}_{2}$ via $\mathrm{H}_{2}$ addition, and $\mathrm{H}^{+} / \mathrm{e}^{-}$equivalents. The work makes use of a novel tris(phosphino) ligand. When a pendent amine is attached to the ligand, no change in catalytic reactivity is observed.
\end{abstract}

Reduction of $\mathrm{CO}_{2}$ to fuels and/or fuel precursors is integral to minimize global warming and advance future energy schemes. ${ }^{1}$ One approach is to use $\mathrm{H}_{2}$ to hydrogenate $\mathrm{CO}_{2}$ to formic acid (FA) or $\mathrm{MeOH}$, though challenges include transportation of the gas, the necessity of high pressures of $\mathrm{H}_{2}$ and/or elevated temperatures required for many catalysts, and improving catalyst performance. Lifecycle analysis for $\mathrm{CO}_{2}$ hydrogenation to FA (using a homogeneous catalyst) suggests that this approach can decrease the net greenhouse gas emissions when compared to FA production from $\mathrm{CO}^{2}$ Despite showing an improvement, this analysis also indicates that $\mathrm{H}_{2}$ production accounts for a significant amount of the emissions. ${ }^{3}$

An alternative method is the solar-derived electrochemical reduction of $\mathrm{CO}_{2} .{ }^{4}$ While the $2 \mathrm{e}^{-} / 2 \mathrm{H}^{+}$reduction of $\mathrm{CO}_{2}$ to $\mathrm{CO}$ is well-established, reduction to $\mathrm{FA}$ has proven more challenging at homogenous systems due to competing $\mathrm{H}_{2}$ production. ${ }^{5}$ This latter reaction can be thought of as an electrochemical hydrogenation. It necessitates a proton source capable of generating a metal hydride, and that the subsequent insertion of $\mathrm{CO}_{2}$ be favoured over loss of $\mathrm{H}_{2}$; both reactions have similar thermodynamic driving forces. ${ }^{4}$ Berben's group showed that selectivity for $\mathrm{FA}$ over $\mathrm{H}_{2}$ can be achieved by exclusion of a pendent proton shuttle, which alters the kinetics of proton transfer to the

Department of Chemistry, University of Utah, 315 S. 1400 E., Salt Lake City, UT, 84112, USA. E-mail: caroline.saouma@utah.edu

$\dagger$ Electronic supplementary information (ESI) available. CCDC 2010200-2010206, 2022544 and 2022545. For ESI and crystallographic data in CIF or other electronic format see DOI: 10.1039/d0cc04310a active-site. ${ }^{6}$ Recently, the groups of Kubiak ${ }^{7}$ and Yang ${ }^{5}$ have shown how $\mathrm{H}_{2}$ production can be circumvented on thermodynamic arguments if the product is formate and not FA.

Given the widespread utility of hydrogenations, advancement of electrochemical alternatives may have significant impact. Waymouth showed that a Ru transfer hydrogenation catalyst can serve as an electrocatalyst for the oxidation of alcohols to ketones; ${ }^{8}$ in this system a cationic solvent species is proposed as an intermediate. With regards to $\mathrm{CO}_{2}$ conversion to formate, Meyer and Brookhart reported that the $2 \mathrm{e}^{-} / 1 \mathrm{H}^{+}$ reduction of a PCP-ligated $\operatorname{IrH}(\mathrm{MeCN})_{2}{ }^{+9}$ gives a species capable of inserting $\mathrm{CO}_{2}$, with subsequent formate release. This system also necessitates a labile solvent molecule to avoid an 18-electron species that cannot be reduced. The limited literature examples of electrocatalytic hydrogenations re-enforce the need for better understanding how the two mechanistic pathways intersect, as well as establishing catalyst design criteria that allows for the desired reactivity.

Herein we describe a new family of Co complexes that perform both hydrogenation and electrocatalytic reduction of $\mathrm{CO}_{2}$ to formate with excellent product selectivity. To our knowledge, this is the first system capable of this dual reactivity: reaction of $\mathrm{CO}_{2}$ with $\mathrm{H}_{2}$ to give $\mathrm{FA}$, and reaction of $\mathrm{CO}_{2}$ with $\mathrm{H}^{+}$and $\mathrm{e}^{-}$equivalents to selectively give $\mathrm{FA}$ (over competing $\mathrm{H}_{2}$ production). Mechanistic studies indicate how the mechanisms are related. The ligand features a pendent amine that does not impact either reaction type.

To explore the dual reactivity of electrocatalytic reduction ${ }^{10,11}$ and hydrogenation ${ }^{12-15}$ of $\mathrm{CO}_{2}$, phosphine-ligated Co complexes were targeted. Electrocatalytic generation of $\mathrm{Co}-\mathrm{H}$ is known to occur for proton reduction catalysts; ${ }^{16}$ one example ${ }^{17}$ employs a tris(phosphino) ligand that has also been shown to catalytically hydrogenate $\mathrm{CO}_{2}$ to $\mathrm{MeOH}$ using Co. ${ }^{18}$ To explore the role that pendent proton-relays may have on both catalytic pathways, a tris(phosphino) scaffold was developed that features a single pendent amine and is flexible in mer/fac coordination to the metal. 

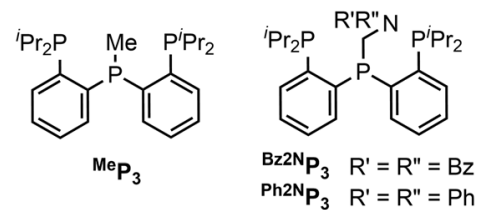

Chart 1 Ligands and abbreviations used in this study.

Tris(phosphino) ligands with a central phosphine that can be functionalized were prepared (Chart 1). The ligands that feature a pendent amine are readily prepared by addition of a suitable amine and paraformaldehyde to the precursor secondary phosphine (see ESI $\dagger$ ). ${ }^{19}$ For this study, two tertiary amines $\left({ }^{\mathbf{B z} 2 \mathbf{N}} \mathbf{P}_{3},{ }^{\mathbf{P h} 2 \mathbf{N}} \mathbf{P}_{3}\right)$ were chosen for the pendent amine. A ligand with no amine, ${ }^{\mathbf{M}} \mathbf{P}_{3}$ was also synthesized. ${ }^{20}$

Metalation of the ligands is achieved by stirring equimolar ligand with $\mathrm{CoCl}_{2}$ or $\mathrm{Co}\left(\mathrm{PPh}_{3}\right)_{3} \mathrm{Cl}$ to give $\left({ }^{\mathbf{R}} \mathbf{P}_{3}\right) \mathbf{C o C l}_{2}$ or $\left({ }^{\mathbf{R}} \mathbf{P}_{3}\right)$ CoCl respectively. Solid-state structures of $\left({ }^{\mathbf{B z} 2 \mathbf{N}} \mathbf{P}_{3}\right) \mathbf{C o C l} \mathbf{l}_{2}$,

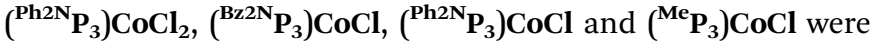
obtained and exemplary structures shown in Fig. 1. All of the Co(II) species feature two inner-sphere chloride ions, and have distorted square pyramidal geometry $(\tau \sim 0.15) .{ }^{21}$ The $\mathrm{Co}(\mathrm{I})$ species are 4-coordinate and are best described as distorted tetrahedral $(\tau \sim 0.75) .{ }^{22}$ In no instances does the amine nitrogen coordinate the metal centre.

Hydrogenation of $\mathrm{CO}_{2}$ under basic conditions was then explored with the $\mathrm{Co}(\mathrm{I})$ complexes (Table 1 ). No $\mathrm{MeOH}$ was observed by GC analysis, and the only product detected was formate.

Entries 1-3 of Table 1 indicate that the base strength impacts catalysis; increasing the base strength from $\mathrm{K}_{3} \mathrm{PO}_{4}$ to $\mathrm{KO}^{t} \mathrm{Bu}$ gives higher turnover number (TON), suggesting that a deprotonation event may limit the catalysis. Two of the $\mathrm{Co}(\mathrm{I}) \mathrm{Cl}$ species gave $\sim$ quantitative TON with respect to base (entries 5 , 8) when 100 eq. $\mathrm{KO}^{t} \mathrm{BU}$ is employed. Increasing the amount of base diminishes catalysis (entries 5-7); a color change is noted when large amounts of base are added to the catalyst solution, suggestive of catalyst degradation. Recycling studies indicate that a viable catalyst is present at the end of catalysis, though the paramagnetic nature of the complexes makes it difficult to ascertain the identity (see $\mathrm{ESI} \dagger$ ).
Table 1 Catalytic hydrogenation of $\mathrm{CO}_{2}$ to formate with $\mathrm{Co}(\mathrm{I})$

\begin{tabular}{|c|c|c|c|c|}
\hline \multirow[b]{2}{*}{ Entry } & \multirow[t]{2}{*}{ base + rO $_{2}+\mathrm{H}_{2}$} & \multicolumn{2}{|c|}{$\underset{120^{\circ} \mathrm{C}, 16 \mathrm{~h}}{\stackrel{5 \mathrm{mmol} \text { catalyst }}{(1 \mathrm{~mol})}}$ HCOO } & \multirow[b]{2}{*}{ Formate $\mathrm{TON}^{c}$} \\
\hline & & Base & Equiv. of base & \\
\hline $1^{a}$ & 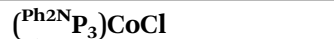 & $\mathrm{K}_{3} \mathrm{PO}_{4}$ & 100 & 12 \\
\hline $2^{a}$ & $\left({ }^{\mathbf{P h} 2 \mathrm{~N}} \mathbf{P}_{3}\right) \mathrm{CoCl}$ & $\mathrm{KO}^{t} \mathrm{Bu}$ & 100 & $65( \pm 6)$ \\
\hline $3^{a}$ & 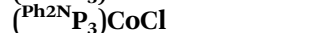 & DBU & 100 & 51 \\
\hline $4^{b}$ & {$\left[\left({ }^{\mathrm{Ph} 2 \mathrm{~N}} \mathbf{P}_{3}\right) \mathrm{Co}(\mathrm{MeCN})\right][\mathrm{BArF}]$} & $\mathrm{KO}^{t} \mathrm{Bu}$ & 100 & $111( \pm 4)$ \\
\hline $5^{b}$ & $\left({ }^{\mathrm{Bz} 2 \mathrm{~N}^{2}} \mathbf{P}_{3}\right) \mathrm{CoCl}$ & $\mathrm{KO}^{t} \mathrm{Bu}$ & 100 & $124( \pm 9)$ \\
\hline $6^{b}$ & $\left({ }^{\mathrm{Bz} 2 \mathrm{~N}} \mathbf{P}_{3}\right) \mathbf{C o C l}$ & $\mathrm{KO}^{t} \mathrm{Bu}$ & 200 & $37( \pm 8)$ \\
\hline $7^{b}$ & $\left({ }^{\mathrm{Bz} 2 \mathrm{~N}} \mathbf{P}_{3}\right) \mathrm{CoCl}$ & $\mathrm{KO}^{t} \mathrm{Bu}$ & 2000 & 242 \\
\hline $8^{b}$ & $\left({ }^{\mathrm{Me}} \mathbf{P}_{3}\right) \mathbf{C o C l}$ & $\mathrm{KO}^{t} \mathrm{Bu}$ & 100 & $122( \pm 6)$ \\
\hline $9^{b}$ & $\left({ }^{\mathrm{Bz} 2 \mathrm{~N}} \mathbf{P}_{3}\right) \mathrm{CoCl}$ & - & - & 9 \\
\hline $10^{b, d}$ & - & $\mathrm{KO}^{t} \mathrm{Bu}$ & 100 & 20 \\
\hline
\end{tabular}

${ }^{a}$ Reactions run in $3 \mathrm{~mL}$ THF, at $150{ }^{\circ} \mathrm{C}$ for $20 \mathrm{~h} .{ }^{b}$ Reactions run in $10 \mathrm{~mL}$ THF with the conditions provided in the scheme. ${ }^{c}$ Average of two runs with standard deviation in parenthesis. If no standard deviation, single run. ${ }^{d}$ Run for $20 \mathrm{~h}$.

To determine if the chloride is pertinent to catalysis, ${ }^{\mathbf{P h} 2 \mathbf{N}} \mathbf{P}_{3} \mathbf{C o C l}$ was treated with NaBArF to give cationic $\left[\left({ }^{\mathbf{P h} 2 \mathbf{N}} \mathbf{P}_{3} \mathbf{C o}\right.\right.$ $(\mathbf{M e C N}))][$ BArF] (BArF = tetrakis[3,5-bis(trifluoromethyl)phenyl] borate), the structure of which is shown in Fig. 1. Using the cation as a catalyst for the hydrogenation of $\mathrm{CO}_{2}$ improves the TON compared to that of the chloride (entries 2 and 4) and indicates that $\sim$ quantitative conversion is possible using complexes of all ligands examined.

A mechanism that includes $\mathrm{CO}_{2}$ insertion into a $\mathrm{Co}-\mathrm{H}$ (to give $\mathrm{Co}-\mathrm{OCHO}$ ) seems plausible and hence this reactivity was explored. Addition of 2 eq. of $\mathrm{NaBHEt}_{3}$ to a stirring THF solution of ${ }^{\mathbf{P h} 2 \mathbf{N}_{\mathbf{P}}} \mathbf{P o C l}_{\mathbf{2}}$ at $-70{ }^{\circ} \mathrm{C}$ results in formation of a new species. The ${ }^{31} \mathrm{P}$ NMR spectrum shows two singlets at 101.6 and 98.9 ppm, suggesting that a single diamagnetic Co(I) species has formed. The corresponding ${ }^{1} \mathrm{H}$ NMR spectrum shows a doublet of triplet at $\mathbf{- 1 1 . 3 5} \mathrm{ppm}$, consistent with a Co-H and IR analysis shows a stretch at $2082 \mathrm{~cm}^{-1}$. Vapor diffusion of benzene into heptane gave crystals suitable for diffraction, and the solid-state structure indicates the formation of a dimeric species, $\left\{{ }^{\mathbf{P h} 2 \mathbf{N}} \mathbf{P}_{3} \mathbf{C o H}\right\}_{2}\left(\boldsymbol{\mu}-\mathbf{N}_{2}\right)$ (Fig. 1). Each Co is 5coordinate with the hydride in the plane of the three phosphines and the $\mathrm{N}_{2}$ coordinating in the apical position.
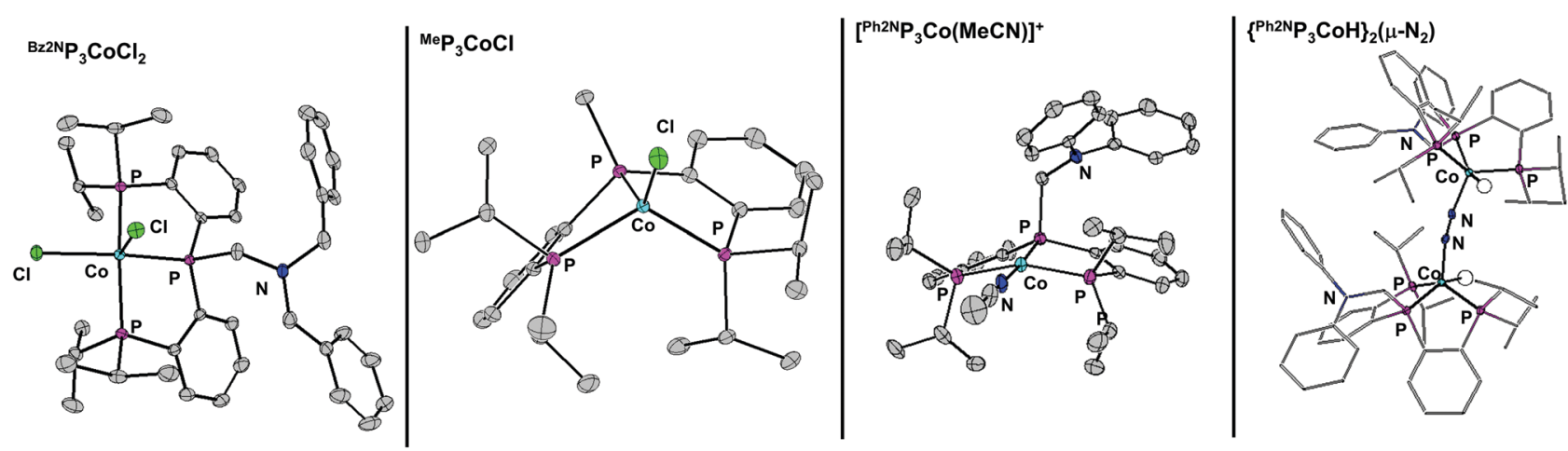

Fig. $150 \%$ thermal ellipsoid plot of several complexes. All hydrogen atoms not located in the difference map are removed for clarity. Only the cation of $\left[\left({ }^{\mathrm{Ph} 2 \mathrm{~N}} \mathrm{P}_{3} \mathrm{Co}(\mathrm{MeCN})\right)\right][\mathrm{BArF}]$ is shown. 
To determine if the hydride is sufficiently hydridic to insert $\mathrm{CO}_{2}, 0.85$ atm of $\mathrm{CO}_{2}$ was added to a solution of $\left\{{ }^{\mathbf{P h} 2 \mathbf{N}} \mathbf{P}_{3} \mathbf{C o H}\right\}_{2}\left(\boldsymbol{\mu}-\mathbf{N}_{2}\right)$. NMR analysis shows complete conversion of the diamagnetic hydride to a new paramagnetic species. Now, the IR spectrum shows disappearance of the hydride resonance and a new peak at $1628 \mathrm{~cm}^{-1}$, consistent with formation of a species such as ${ }^{\mathbf{P h} 2 \mathbf{N}} \mathbf{P}_{\mathbf{3}}$ Co-OCHO. The related species, $\left(\mathrm{PPh}_{3}\right)_{3} \mathrm{Co}(\mathrm{H})\left(\mathrm{N}_{2}\right)$, inserts $\mathrm{CO}_{2}$ to give $\left(\mathrm{PPh}_{3}\right)_{3} \mathrm{Co}(\mathrm{OCHO}),{ }^{23}$ and the corresponding formate stretch is at $1620 \mathrm{~cm}^{-1}$.

A proposed mechanism is shown in Scheme 1. Entry into the catalytic cycle occurs from the reaction of ${ }^{\mathbf{R}} \mathbf{P}_{3} \mathbf{C o C l}$ with $\mathrm{H}_{2}$ and base, which would give a 5-coordinate species such as ${ }^{\mathbf{R}} \mathbf{P}_{3} \mathbf{C o}(\mathbf{H})(\mathbf{L})\left(\mathrm{L}=\mathrm{N}_{2}\right.$ or solvent). Subsequent insertion of $\mathrm{CO}_{2}$ gives ${ }^{\mathbf{R}} \mathbf{P}_{\mathbf{3}}$ Co-OCHO. The resulting 16-electron species ${ }^{\mathbf{R}} \mathbf{P}_{\mathbf{3}}$ Co-OCHO may then coordinate $\mathrm{H}_{2}$ to give the proposed 18-electron ${ }^{\mathrm{R}} \mathbf{P}_{\mathbf{3}} \mathbf{C o}\left(\mathbf{H}_{2}\right)$ OCHO. Base-mediated deprotonation of the bound $\mathrm{H}_{2}$ coupled with formate loss regenerates ${ }^{\mathbf{R}} \mathbf{P}_{3} \mathbf{C o}(\mathbf{H})(\mathbf{L})$. Another mechanism would be deprotonation of the bound $\mathrm{H}_{2}$ by the inner-sphere formate to generate ${ }^{\mathbf{R}} \mathbf{P}_{3} \mathbf{C o}(\mathbf{H})(\mathbf{L})$ and formic acid (B = formate in Scheme 1). Indeed, this may explain the $>100$ TON (entries 4,5 , 8) when only 100 equivalents of base is added, as well as the low TON obtained in the absence of base (entry 9). This is proposed to be a minor pathway that is viable in the absence of base, that proceeds with slower kinetics.

An alternative mechanism that has been proposed for related complexes is that the formate dissociates from the Co to give $\left.{ }^{\mathbf{P h} 2 \mathbf{N}} \mathbf{P}_{3} \mathbf{C o}(\mathbf{M e C N})\right]^{+}$and free formate (Scheme 1, inner pathway). The cation then coordinates $\mathrm{H}_{2}$ and base-mediated deprotonation of the bound $\mathrm{H}_{2}{ }^{12}$ or oxidative addition product (not shown) then ensues. ${ }^{13,14}$ Given that both $\left[{ }^{\mathbf{P h} 2 \mathbf{N}_{\mathbf{P}}} \mathbf{P}_{\mathbf{3}} \mathbf{C o}(\mathbf{M e C N})\right]^{+}$and ${ }^{\mathbf{R}} \mathbf{P}_{\mathbf{3}} \mathbf{C o}-\mathbf{O C H O}$ are stable, this seems unlikely. Moreover, in related work on $\mathrm{Ru}$ we have shown that binding of formate to a cationic Ru centre is favorable. $^{24}$

Though it was envisioned that the pendent amine may facilitate deprotonation of $\mathrm{H}_{2}$ via hydrogen-bonding, ${ }^{25}$ the similar catalytic performances amongst all the catalysts indicates that such an effect, if present, is irrelevant in the catalytic hydrogenations investigated.

With the feasibility to hydrogenate $\mathrm{CO}_{2}$ to formate established, we sought to determine if electrocatalytic hydrogenation of $\mathrm{CO}_{2}$ is also accessible. The cyclic voltammograms (CVs) of several complexes are shown in Fig. 2. Cationic $\left[{ }^{\mathbf{P h} 2 \mathbf{N}} \mathbf{P}_{3} \mathbf{C o}(\mathbf{M e C N})\right]^{+}$shows a reversible reduction at $-0.863 \mathrm{~V}\left(v s . \mathrm{Fc}^{+/ 0}\right)$ that corresponds to the $\mathrm{Co}(\mathrm{II} / \mathrm{I})$ couple. A second reduction event occurs at $\sim-1.9 \mathrm{~V}$,

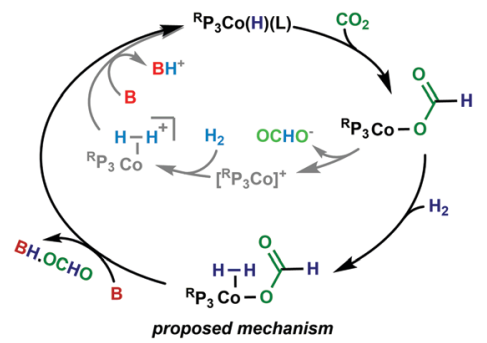

Scheme 1 Proposed mechanism for hydrogenation of $\mathrm{CO}_{2}$ to formate, with alternate mechanism shown in grey.

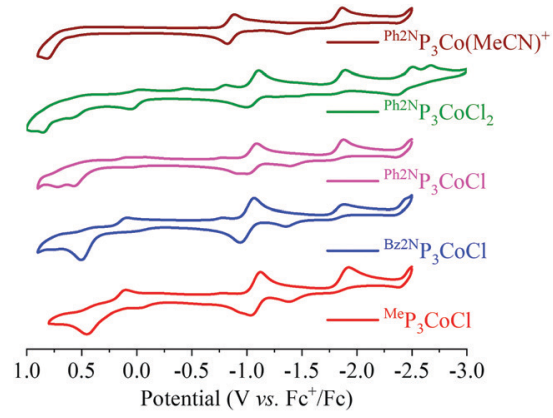

Fig. 2 Cyclic voltammograms of the various Co complexes. Conditions: GC working electrode, 0.1 $\mathrm{M} \mathrm{TBAPF}_{6}$ electrolyte in $\mathrm{MeCN}$. Initial scan is in the positive direction.

with a return oxidation at $\sim-1.3 \mathrm{~V}$. This tentatively is assigned to the $\mathrm{Co}(\mathrm{I} / 0)$ couple. Consistent with this, the reaction of ${ }^{\mathbf{P h} 2 \mathbf{N}} \mathbf{P}_{3} \mathbf{C o C l}$ with $\mathrm{Na} / \mathrm{Hg}$ gives ${ }^{\mathbf{P h} 2 \mathbf{N}_{\mathbf{P}}} \mathbf{P}_{\mathbf{3}} \mathbf{C o}\left(\mathbf{N}_{2}\right)$ (see ESI $\dagger$ ); the irreversible nature of the couple is attributed to $\mathrm{N}_{2}$ coordination upon reduction. The irreversibility may also be attributed to different numbers and types of L-type ligands upon reduction ( $\mathrm{L}=\mathrm{MeCN}$ or $\mathrm{N}_{2}$ ). The CVs

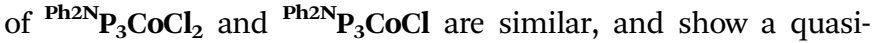
reversible reduction at $-1.050 \mathrm{~V}$. Both $\mathrm{CVs}$ show peaks that correspond to $\left[{ }^{\mathbf{P h} 2 \mathbf{N}} \mathbf{P}_{3} \mathbf{C o}(\mathbf{M e C N})\right]^{+}$, consistent with chloride loss upon reduction to $\mathrm{Co}(0)$. Notably, the peaks that correspond to the second reduction are super-imposable with those in the CV of $\left[\left({ }^{\mathbf{P h} 2 \mathbf{N}_{\mathbf{P}}} \mathbf{C o}(\mathbf{M e C N})\right)\right]^{+}$. Modest changes in the reduction potentials is anticipated as the $\mathrm{R}$ group on the central phosphine is varied. ${ }^{10}$ Indeed, the Co(II/I) potential of ${ }^{\mathbf{B z} 2 \mathbf{N}} \mathbf{P}_{3} \mathbf{C o C l}$ occurring at $-1.013 \mathrm{~V}$, and that of ${ }^{\mathrm{Me}} \mathbf{P}_{3} \mathbf{C o C l}$ at $-1.089 \mathrm{~V}$.

In the presence of 50 eq. water, no noticeable changes to the CVs are observed for all ${ }^{\mathbf{R}} \mathbf{P}_{\mathbf{3}}$ CoCl (Fig. 3 and ESI $\dagger$ ). However, upon addition of $\mathrm{CO}_{2}$, a catalytic current is observed, suggesting formation of $\mathrm{CO}$ or formate. The current increases further with 1617 eq. $\mathrm{H}_{2} \mathrm{O}$ ( $3 \%$ by volume, see $\mathrm{ESI} \dagger$ ) at potentials close to the $\mathrm{Co}^{\mathrm{I} / 0}$ couple; other $\mathrm{Co}$ electrocatalysts reduce $\mathrm{CO}_{2}$ at potentials well shifted from the redox couples of the catalyst. ${ }^{10}$ Indeed, rapid current enhancement at $\sim-2.5 \mathrm{~V}$ suggests that there may be two pathways for catalytic reduction.

Controlled potential electrolysis with $3 \%$ water and $0.85 \mathrm{~atm}$ of $\mathrm{CO}_{2}$ at $-2.1 \mathrm{~V} v$ s. Fc/Fc ${ }^{+}$was conducted using ${ }^{\mathrm{Me}} \mathbf{P}_{3} \mathbf{C o C l}$ and

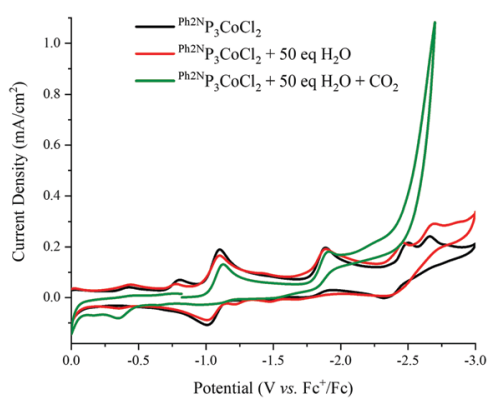

Fig. 3 Cyclic voltammograms of $1 \mathrm{mM}{ }^{\mathrm{Ph} 2 \mathrm{~N}} \mathrm{P}_{3} \mathrm{CoCl}_{2}$ under various conditions. (Black): under $\mathrm{N}_{2}$; (red): in the presence of 50 eq. $\mathrm{H}_{2} \mathrm{O}$; (green): in the presence of 50 eq. $\mathrm{H}_{2} \mathrm{O}$ and $\mathrm{CO}_{2}$. Conditions: $\mathrm{GC}$ working electrode, $0.1 \mathrm{M} \mathrm{TBAPF}_{6}$ electrolyte in $\mathrm{MeCN}$ solvent, scan rate of $0.06 \mathrm{~V} \mathrm{~s}^{-1}$, initial scan is positive. 
Table 2 Product distribution of the controlled potential electrolysis (CPE) experiments $^{a}$

\begin{tabular}{llll}
\hline Complex & $\mathrm{FE}^{b} \mathrm{H}_{2}$ & $\mathrm{FE}^{b} \mathrm{CO}$ & $\mathrm{FE}^{b} \mathrm{HCOO}^{-}$ \\
\hline${ }^{\mathrm{Me}} \mathbf{P}_{\mathbf{3}} \mathbf{C o C l}$ & $2.5( \pm 2.8)$ & $\mathrm{nd}^{c}$ & $58( \pm 15)$ \\
${ }^{\mathrm{Bz} 2 \mathbf{P}_{3} \mathbf{C o C l}}$ & $3.2( \pm 0.4)$ & $\mathrm{nd}^{c}$ & $36( \pm 18)$
\end{tabular}

${ }^{a}$ See ESI. ${ }^{b}$ Faradaic efficiency; average of four runs, standard deviation given in parentheses. ${ }^{c}$ None detected.

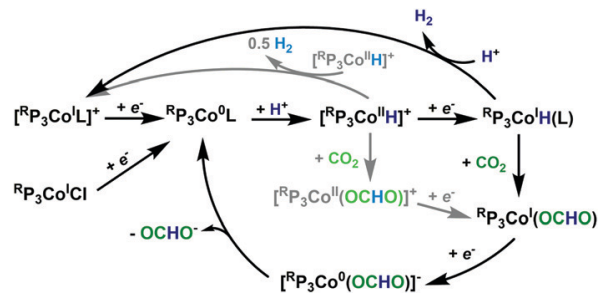

Scheme 2 Proposed (black) \& alternative (gray) mechanisms for $\mathrm{CO}_{2}$ and $\mathrm{H}^{+}$reduction.

${ }^{\text {Bz2N }}{ }_{\mathbf{P}_{3}} \mathbf{C o C l}$ as the catalyst (Table 2). This potential is chosen to see if catalysis does occur near the reduction potential of the complexes. In both instances, no CO was detected in the headspace, and $\mathrm{H}_{2}$ is only produced in small quantities with both catalysts. No other gaseous products are produced, and the solution phase shows the presence of formate and $\mathrm{MeOH}$.

The catalysts are stable, as ascertained by CVs after electrolysis and the steady current (see ESI $\dagger$ ).

A proposed mechanism is shown in Scheme 2. Upon reduction to ${ }^{\mathbf{R}} \mathbf{P}_{3} \mathbf{C o}^{\mathbf{0}} \mathbf{L}$ ( $\mathrm{L}=\mathrm{N}_{2}$ or solvent), protonation ensues to give $\left[{ }^{\mathbf{R}} \mathbf{P}_{3} \mathbf{C o}{ }^{\mathbf{I I}} \mathbf{H}\right]^{+}$. This is reduced at the electrode to give ${ }^{\mathbf{R}} \mathbf{P}_{\mathbf{3}} \mathbf{C o}{ }^{\mathbf{I}} \mathbf{H}$, which then inserts $\mathrm{CO}_{2}$ to give ${ }^{\mathbf{R}} \mathbf{P}_{\mathbf{3}} \mathbf{C o} \mathbf{o}^{\mathbf{I}}$ (OCHO); this sequence being identical to that in the hydrogenation reaction. Reduction to ${ }^{\mathbf{R}} \mathbf{P}_{\mathbf{3}} \mathbf{C o}^{\mathbf{0}}$ (OCHO) and subsequent formate release then regenerates ${ }^{{ }^{\mathbf{R}}} \mathbf{P}_{\mathbf{3}} \mathbf{C o}^{\mathbf{0}} \mathbf{L}$. The lack of lability of the formate in ${ }^{\mathbf{R}} \mathbf{P}_{\mathbf{3}} \mathbf{C o}{ }^{\mathbf{I}}$ (OCHO) and the cathodic potential of catalysis is consistent with this EC mechanism. While we cannot rule out initial $\mathrm{CO}_{2}$ insertion to $\left[{ }^{\mathrm{R}} \mathbf{P}_{\mathbf{3}} \mathbf{C o}{ }^{\mathrm{II}} \mathbf{H}\right]^{+}$followed by reduction, this reactivity is not known for this system. Finally, the $\mathrm{pH}$ of the solution increases during the course of catalysis, indicating that formate and not formic acid is lost.

Regarding proton reduction, the following can be gleaned. As ${ }^{\mathbf{R}} \mathbf{P}_{3} \mathbf{C o}{ }^{\mathbf{I}} \mathbf{H}$ is stable, we rule out a bimetallic mechanism that would generate ${ }^{\mathbf{R}} \mathbf{P}_{\mathbf{3}} \mathbf{C o}{ }^{\mathbf{0}} \mathbf{L}$. A bimetallic mechanism from $\left[{ }^{\mathbf{R}} \mathbf{P}_{3} \mathbf{C o}{ }^{\text {II }}-\mathbf{H}\right]^{+}$also seems unlikely, as it would not explain why $\mathrm{H}_{2}$ is only produced in the presence of pendent amines; these species are also more sterically encumbering and hence should minimize this pathway on steric grounds. Protonation of ${ }^{\mathbf{R}} \mathbf{P}_{\mathbf{3}} \mathbf{C o}{ }^{\mathbf{I}} \mathbf{H}$ seems most plausible, and literature precedence is consistent with proton relays enhancing $\mathrm{H}_{2}$ production over formate. ${ }^{6}$

The work presented here provides the first example of a welldefined catalyst that can hydrogenate $\mathrm{CO}_{2}$ to formate and electrocatalytically reduce $\mathrm{CO}_{2}$ to formate. Notably, the latter reaction occurs with good selectivity for formate. The stability of several intermediates, including a cationic solvent species that seems essential for the dual reactivity, allows for further mechanistic insight. Optimization studies and detailed mechanistic work is ongoing.

The authors gratefully acknowledge the NSF CAREER (1945646), NSF REU (1659579) and start-up funds. NIH provided funds for the NMR facilities (1S10OD25241-01, 1C06RR01753901A1, 3R01GM063540-17W1). We acknowledge Dr. Stacey J. Smith and BYU for the use of their single crystal X-ray instrumentation.

\section{Conflicts of interest}

There are no conflicts to declare.

\section{Notes and references}

1 W.-H. Wang, Y. Himeda, J. T. Muckerman, G. F. Manbeck and E. Fujita, Chem. Rev., 2015, 115, 12936-12973.

2 A. Sternberg, C. M. Jens and A. Bardow, Green Chem., 2017, 19, 2244-2259.

3 J. Artz, T. E. Müller, K. Thenert, J. Kleinekorte, R. Meys, A. Sternberg, A. Bardow and W. Leitner, Chem. Rev., 2018, 118, 434-504.

4 R. Francke, B. Schille and M. Roemelt, Chem. Rev., 2018, 118, 4631-4701.

5 B. M. Ceballos and J. Y. Yang, Proc. Natl. Acad. Sci. U. S. A., 2018, 115, 12686-12691.

6 N. D. Loewen, E. J. Thompson, M. Kagan, C. L. Banales, T. W. Myers, J. C. Fettinger and L. A. Berben, Chem. Sci., 2016, 7, 2728-2735.

7 K. M. Waldie, A. L. Ostericher, M. H. Reineke, A. F. Sasayama and C. P. Kubiak, ACS Catal., 2018, 8, 1313-1324.

8 K. M. Waldie, K. R. Flajslik, E. McLoughlin, C. E. D. Chidsey and R. M. Waymouth, J. Am. Chem. Soc., 2017, 139, 738-748.

9 P. Kang, C. Cheng, Z. Chen, C. K. Schauer, T. J. Meyer and M. Brookhart, J. Am. Chem. Soc., 2012, 134, 5500-5503.

10 S. Roy, B. Sharma, J. Pécaut, P. Simon, M. Fontecave, P. D. Tran, E. Derat and V. Artero, J. Am. Chem. Soc., 2017, 139, 3685-3696.

11 F.-W. Liu, J. Bi, Y. Sun, S. Luo and P. Kang, ChemSusChem, 2018, 11, $1656-1663$.

12 A. Z. Spentzos, C. L. Barnes and W. H. Bernskoetter, Inorg. Chem., 2016, 55, 8225-8233.

13 M. S. Jeletic, M. T. Mock, A. M. Appel and J. C. Linehan, J. Am. Chem. Soc., 2013, 135, 11533-11536.

14 M. V. Vollmer, J. Ye, J. C. Linehan, B. J. Graziano, A. Preston, E. S. Wiedner and C. C. Lu, ACS Catal., 2020, 10, 2459-2470.

15 Y. M. Badiei, W.-H. Wang, J. F. Hull, D. J. Szalda, J. T. Muckerman, Y. Himeda and E. Fujita, Inorg. Chem., 2013, 52, 12576-12586.

16 E. S. Rountree, D. J. Martin, B. D. McCarthy and J. L. Dempsey, ACS Catal., 2016, 6, 3326-3335.

17 S. C. Marinescu, J. R. Winkler and H. B. Gray, Proc. Natl. Acad. Sci. U. S. A., 2012, 109, 15127-15131.

18 J. Schneidewind, R. Adam, W. Baumann, R. Jackstell and M. Beller, Angew. Chem., Int. Ed., 2017, 56, 1890-1893.

19 E. Payet, A. Auffrant, X. F. Le Goff and P. L. Floch, J. Organomet. Chem., 2010, 695, 1499-1506.

20 Y.-E. Kim, J. Kim and Y. Lee, Chem. Commun., 2014, 50, 11458-11461.

21 A. W. Addison, T. N. Rao, J. Reedijk, J. van Rijn and G. C. Verschoor, J. Chem. Soc., Dalton Trans., 1984, 1349-1356, DOI: 10.1039/ DT9840001349.

22 L. Yang, D. R. Powell and R. P. Houser, Dalton Trans., 2007, 955-964, DOI: $10.1039 / \mathrm{B} 617136 \mathrm{~B}$

23 L. S. Pu, A. Yamamoto and S. Ikeda, J. Am. Chem. Soc., 1968, 90, 3896.

24 C. L. Mathis, J. Geary, Y. Ardon, M. S. Reese, M. A. Philliber, R. T. VanderLinden and C. T. Saouma, J. Am. Chem. Soc., 2019, 141, 14317-14328.

25 M. Rakowski Dubois and D. L. Dubois, Acc. Chem. Res., 2009, 42, 1974-1982. 